\section{Volume versus quality}

The RCGP encourages the shift to longer appointments to support the care of the ageing population with its polymorbidities. ${ }^{1}$ However, there is a counter-pressure from the NHS in England towards ensuring a minimum number of appointments per thousand patients. The recommendation is currently 72 appointments per thousand patients per week. Some clinical commissioning groups have provided practices with software to monitor appointment availability.

Mental health disorders are generally not well recognised or managed in primary care. $^{2-5}$ The Centre for Mental Health reports that the societal impact of mental health problems in purely monetary terms was $€ 34.9$ bn in 2016/2017 in the UK.

The shift towards minimum number of weekly appointments presents a volume versus quality conflict and where the volume paradigm prevails it is likely that the care of patients with complex needs, including mental health disorders, or polymorbidities will be less well served. Likely too is an undermining of GP resilience and an exacerbation of shortfalls in the GP workforce.

\section{Bennett NE Quinn,}

GP, Blackheath Medical Centre, Moreton,

Wirral, Merseyside.

Email: bennett.quinnanhs.net

\section{REFERENCES}

1. Royal College of General Practitioners. Fit for the future: a vision for general practice. London: RCGP, 2019. https://www.rcgp.org.uk/policy/fit-for-thefuture.aspx (accessed 7 Jan 2020)

2. Andersen SM, Harthorn BH. The recognition, diagnosis, and treatment of mental disorders by primary care physicians. Med Care 1989; 27(9): 869-886.

3. Howe A. Detecting psychological distress: can general practitioners improve their own performance? $\mathrm{Br} J$ Gen Pract 1996; 46(408): 407-410.

4. Smith RC. Educating trainees about common menta health problems in primary care: a (not so) modest proposal. Acad Med 2011; 86(11): e16. DOI: 10.1097/ ACM.0b013e3182308dc8.

5. Wittchen HU, Mühlig S, Beesdo K. Mental disorders in primary care. Dialogues Clin Neurosci2003; 5(2): 115-128.

\section{Non-attendance for cancer investigation}

Jefferson et al ${ }^{1}$ demonstrate the fallibility of the supposedly straightforward '2-week wait' system for ensuring prompt investigation of 'suspected cancer' patients. A 5-7\% failure rate may not seem alarming. but it is the vulnerable, as always, for whom the system fails. And I suspect the true failure rate is higher still because the vulnerable are less likely to consent in research.?

No one emerges blameless from this sad exploration of GP practice. Some GPs have abandoned their patient advocate role or even their willingness to explain and clarify. Blaming workload is not valid. Taking time to ensure patients understand and are safetynetted is essential general practice. The ideal is that the patient leaves the surgery with an appointment in their hand, fully understanding what to expect. Receiving hospital departments often seem insensitive and difficult to contact. And patients who are borderline of inclusion criteria land the Gaussian reality of biological variables means these are inevitable) are worst treated of all. Balint's 'collusion of anonymity' speaks to us from half a century ago. ${ }^{3}$

If GPs lack the time or skills to provide quality care for these important patients, perhaps practices might employ a 'fixer' to support them and help them cut through the bureaucracy.

\section{Arnold G Zermansky,}

Visiting Senior Research Fellow, School of Healthcare, University of Leeds.

Email: a.g.zermanskylaleeds.ac.uk

\section{REFERENCES}

1. Jefferson L, Atkin K, Sheridan R, et al. Nonattendance at urgent referral appointments for suspected cancer: a qualitative study to gain understanding from patients and GPs. $\mathrm{Br} J$ Gen Pract 2019; DOI: https://doi.org/10.3399/ bjgp19X706625.

2. Petty DR, Zermansky AG, Raynor DK, et al. 'No thank you': why elderly patients declined to participate in a research study. Pharm World Sci 2001: 23(1): 22-27.

3. Balint M. The doctor, his patient and the illness. London: Pitman, 1957.

\section{Meeting with your practice psychiatrist}

Lovely article. ${ }^{1}$ This is what used to happen with those fortunately rare major psychiatric emergencies often in the context of thinking about the need to section a patient under the Mental Health Act. A phone call to the secretary, a mutually agreed time, and off we went.

Now a phone call to the local referral unit and a rejection or promises to be phoned back, then the wrong team, then more phone calls, more rejections, and 2 hours have gone past, and the rest of the day's workload cannot be postponed to find a gap for a joint meeting. Shame.

\section{John Sharvill,}

GP, Locum, East Kent.

Email: john.sharvillanhs.net

\section{REFERENCE}

1. Shweta M. Viewpoint: exemplary collaboration with a GP and psychiatrist. Br J Gen Pract 2019; DOI: DOI: https://doi.org/10.3399/bjgp19X706769.

DOI: https://doi.org/10.3399/bjgp20X707813

\section{Correction}

In the Editorial by Barron L and Gordon D. Cannabis in primary care. Br J Gen Pract 2019; DOI: https:// doi.org/10.3399/bjgp19X706673 competing interests should have been declared: Leon Barron has provided unpaid, voluntary medical advice to the Medical Cannabis Clinics and the Academy of Medical Cannabis (to June 2019). Since writing the editorial he has set up the Primary Care Cannabis Network, an education platform for GPs, with no industry links or commercial involvement. Dani Gordon has provided consultancy advice for companies working on medical uses of cannabis, and is the author of a forthcoming book. The CBD Bible.

DOI: https://doi.org/10.3399/bjgp20X708809 